\title{
Artemisia absinthium
}

National Cancer Institute

\section{Source}

National Cancer Institute. Artemisia absinthium. NCI Thesaurus. Code C95757.

An herbal remedy containing the leaves and/or flowering tops of a species of wormwood (Artemisia absinthium) with potential anticachexia activity. Upon oral consumption, Artemisia absinthium may decrease production of pro-inflammatory cytokines such as TNF-alpha. As increased levels of pro-inflammatory cytokines is correlated with decreased appetite and weight loss, Artemisia absinthium may increase appetite and improve weight gain. 